\title{
Attitudes to death of nurses in Turkey and factors affecting them
}

\begin{abstract}
Background: The aim of this study was to determine the attitudes of nurses in Turkey to death, and the factors affecting this.
\end{abstract}

Methods: The research was conducted with 390 nurses working in various departments of a university medical faculty hospital. A demographic questionnaire was given to the nurses to determine socio-demographic characteristics, and the DAP-R was used.

Results: A majority of the nurses in our study $(86.2 \%)$ believed terminal stage health care in Turkey to be inadequate; $46.7 \%$ thought that they themselves were partially inadequate with regard to terminal stage patient care, and a majority $(76.4 \%)$ wanted to have psychosocial training in final stage patient care. The nurses' mean scores on the DAP-R were as follows: fear of death $4.7 \pm 1.18$, avoidance of death $3.92 \pm 1.28$, neutral acceptance of death $5.22 \pm 0.88$, approach-oriented acceptance of death $4.69 \pm 0.94$, and escape-oriented acceptance of death $3.59 \pm 1.16$. Among the factors affecting attitudes to death, a positive correlation was found between age and escape acceptance of death ( $p=0.001 \mathrm{r}: 0.168)$ and a statistically significant relationship was found between marital status and fear of death, between education (professional experience) and escape acceptance and neutral acceptance of death, and between place of work and neutral and approach acceptance of death $(\mathrm{p}<0.05)$.

Conclusion: It was found that nurses sometimes saw death as an unavoidable reality. However, it was concluded that this attitude was not reflected in daily life, that death is turned into a complete crisis, and that we still treat death as a taboo subject.
Volume 2 Issue 6 - 2018

\author{
Hanife Ozcelik,' Fatma Aksoy, ${ }^{2}$ Esra Sonmez, ${ }^{2}$ \\ Cicek Fadiloglu ${ }^{3}$ \\ 'Zubeyde Hanim School of Health, Nigde Omer Halisdemir \\ University, Turkey \\ ${ }^{2}$ Department of Medical Oncology, Faculty of Medicine Hospital, \\ Ege University, Turkey \\ ${ }^{3}$ Faculty of Nursing, Ege University, Turkey
}

\section{Correspondence: Hanife Ozcelik, PhD, RN, Assistant} Professor, Zubeyde Hanim School of Health, Nigde Omer Halisdemir University, 5I I00, Nigde, Turkey, Tel 90388 2II 2839, Email hanifeozcqlik@hotmail.com

Received: November 01, 2018 | Published: November 08, 2018

\section{Introduction}

Death is a fact in everyone's life. Feifel ${ }^{1}$ wrote, "Dying and death are events that happen to each one of us. We can postpone, gain reprieves, but ultimately we all must die...". ${ }^{1,2}$ Although death is a universal experience shared by everyone, in Turkey it remains so some extent a taboo subject in many social groups. ${ }^{3,4}$ Death in most cultures is met with denial, rejection, and fear of the unknown. ${ }^{5,6}$

Dying does not simply imply the single moment in time when life ends, but can also be thought of as a transitional process, the onset of which is rarely clear. ${ }^{7}$ All humans experience death, whether their own or that of others, at one time or another, but that does not mean every human experiences it in the same way. People's attitudes toward death differ depending on an individual's unique life experiences, cultural background, and the personal meaning they ascribe to it. ${ }^{8}$

Throughout their professional history, nurses have sought ways to improve the quality of life for individuals, families and communities during every phase of life. Nurses spend more time with people who are facing death than any other member of the health care team., ${ }^{9,10}$ The burden of dealing with dying patients and their families thus falls constantly and predominantly upon nursing personnel. Yet even though nurses are charged with the care of the dying patient they are not always adequately able to do so. The daily task of working with dying patients may be given to a nurse who is too often poorly prepared to understand, comfort and support them. ${ }^{9}$ Dakin ${ }^{11}$ stated that it is an expectation of the general public that nurses will be kind and compassionate to patients and their families throughout the process of disease or conditions leading to death. Yet nurses often have conflicting feelings resulting from the need to be both compassionate and professional while caring for a wide variety of patients. ${ }^{11}$
Health practitioners face many challenges when caring for and communicating with a dying person. The three most frequent factors identified are dealing with the physician, the patient's family and the general fear surrounding death. Additional problems which may play a part are lack of adequate communication, lack of knowledge, lack of time, and lack of support from hospital management. ${ }^{7,9}$ A Canadian study highlights nurses' reflections on the challenges involved in discussing difficult issues around end-of-life care and feeling unprepared for these conversations. ${ }^{12}$ Sasahara et al. ${ }^{13}$ reported that $92 \%$ of nurses encountered difficulties in helping patients express their anxiety, anger, and concerns; $91 \%$ were unsure how to react when patients talked about death and dying. It is thus important to explore nurses' attitudes toward caring for dying patients and to develop strategies to alleviate these communication difficulties between nurses and patients to improve care in the terminal phase. ${ }^{13,14}$ Researchers in both the West and Taiwan have reported that health care providers' values and belief systems relating to death are heavily influenced by their own internal thoughts and deeper feelings, which, in turn, are a reflection of their personal and interpersonal experiences. ${ }^{15}$ Nurses often experience great struggles in coping with these. Some writers have also suggested that nurses' anxieties in caring for dying people are strongly related to the fear of their own death. Thus, nurses need to recognize and confront their own reactions to death before they can assist their patients. ${ }^{15}$

According to Rooda et al. ${ }^{16}$ the factors determining attitudes toward death and caring for dying patients are numerous and complex. These determinants include the cultural, societal, philosophical, and religious belief systems that give meaning to death, as well as personal and cognitive frameworks within which individuals' attitudes toward death and dying originate and are interpreted. 
Studies have found that people have widely varying attitudes toward death, some positive and some negative. Fear of death is the attitude investigated most frequently. ${ }^{17}$ Rooda et al. ${ }^{16}$ interviewed 403 nurses working in different departments who had little experience in caring for dying patients. They found that attitudes toward caring for terminal patients were negative when associated with fear of death and need to avoid it, and positively associated with a neutral acceptance of death. ${ }^{16,18}$

Some research studies suggest that demographic characteristics influence nurses' attitudes toward terminally ill patients. Some have reported that as age and years of experience increase, nurses tend to show more positive attitudes toward terminally ill and dying patients. ${ }^{5,19,20}$ Bradley et al. ${ }^{19}$ suggested that previous studies of the clinicians' attitudes to caring for dying patients had created inconsistent results in the literature that made it more complex to achieve a final consensus. Some studies have shown that as clinicians gain more experience with terminal and end-of-life care, their attitudes become more positive. ${ }^{19}$ However, Demmer's ${ }^{21}$ study revealed a significant relationship between personal experiences of death, anxiety about death and attitudes toward dying patients. They stated that as the years of experience increase, the attitudes of nurses toward dying patients become more negative or are not influenced. ${ }^{5,20-22}$ The aim of this study was to determine the attitudes of nurses in Turkey to death, and the factors affecting these.

\section{Material and methods}

\section{Design and setting}

This study, aimed at determining the attitudes to death of nurses in Turkey and the factors affecting them, was of a descriptive type. It was conducted in all service and intensive care units at a university hospital in Izmir, Turkey between October 2011 and February 2012. The research sample consisted of 390 nurses working in various services of this medical faculty hospital, all of whom agreed to take part in the study.

\section{Instruments}

The nurses included in the study were given a Sociodemographic Characteristics Questionnaire and the Death Attitudes Profile-Revised (DAP-R) developed by Wong et al. ${ }^{23}$ Collection of research data was performed by face-to-face interview with the nurses.

The Sociodemographic Characteristics Data Form was devised by the researchers to obtain information on the sociodemographic characteristics of the individuals, and included questions on such variables as age, gender, education level, marital status, social security and income level.

The Death Attitudes Profile-Revised (DAP-R), developed by Wong et al. ${ }^{23}$ to measure attitudes to death, was used..$^{23}$ Validity and reliability testing of this scale for the Turkish population was performed by Iş1k et al. ${ }^{24}$ in and the Cronbach alpha of the scale was calculated as $0.81 .{ }^{24}$ The scale measured respondees' attitudes on a seven-point Likert scale from 'I entirely disagree' to 'I entirely agree'. It presented a multi-dimensional model including five attitudes towards death. The scale consisted of five sub-factors: fear of death (seven items), escapeoriented acceptance (five items), neutral acceptance (five items), approach-oriented acceptance (ten items) and avoidance of death (five items). The scores of all items ranged from 1: 'I entirely disagree', to 7: 'I entirely agree'. A mean score on the scale for each dimension was calculated by dividing the total scale score by the number of items in each scale.

\section{Statistical analyses and ethics}

SPSS version 13.0 was used for analysis of the research data. We used descriptive statics and Pearson correlations to examine whether the attitudes to death of nurses varied by socio-demographic characteristics. For all analyses, $\mathrm{P}<0.05$ was considered significant. Permission to conduct the research was obtained from the Ege University ethics committee, the medical faculty hospital and the nurses themselves.

\section{Results}

\section{Demographic description of participating nurses}

The mean age of the nurses participating in the study was $32.28 \pm 7.3$ years. It was found that $98.7 \%$ were female, $59.2 \%$ were married, $81.3 \%$ were university graduates, $32.1 \%$ had been working for 13 or more years, and $54.1 \%$ were working as service nurses (Table 1).

Table I Demographics and professional characteristics of nurses

\begin{tabular}{|c|c|c|}
\hline & $\mathbf{n}$ & $\%$ \\
\hline Age & $32,28 \pm 7,379$ & \\
\hline \multicolumn{3}{|l|}{ Gender } \\
\hline Female & 385 & 98.7 \\
\hline Male & 5 & $\mathrm{I} .3$ \\
\hline \multicolumn{3}{|l|}{ Marital status } \\
\hline Married & 231 & 59.2 \\
\hline Single & 146 & 37.4 \\
\hline Divorced & 13 & 3.3 \\
\hline \multicolumn{3}{|l|}{ Education status } \\
\hline High school & 7 & 1.8 \\
\hline Associate degree & 38 & 9.7 \\
\hline Bachelor's degree & 317 & 81.3 \\
\hline Master's degree & 28 & 7.2 \\
\hline \multicolumn{3}{|l|}{ Years of work } \\
\hline Less than I year & 33 & 8.5 \\
\hline I-3 years & 51 & 13.1 \\
\hline $4-6$ years & 85 & 21.8 \\
\hline 7- 9 years & 66 & 16.9 \\
\hline $10-12$ years & 30 & 7.7 \\
\hline More than 13 years & 125 & 32.1 \\
\hline \multicolumn{3}{|l|}{ Workplace } \\
\hline Surgery departments & 148 & 37.9 \\
\hline Internal medicine departments & 138 & 35.4 \\
\hline Oncology departments & 46 & 11.8 \\
\hline Transplantation department & 21 & 5.4 \\
\hline Anesthesia intensive care unit & 37 & 9.5 \\
\hline \multicolumn{3}{|l|}{ Nursinge role } \\
\hline Head nurse & 41 & 10.6 \\
\hline Staff nurse & 211 & 54.1 \\
\hline Care unit nurse & 91 & 23.3 \\
\hline Others & 47 & 12.1 \\
\hline Total & 390 & 100 \\
\hline
\end{tabular}


It was stated by $76.2 \%$ of the nurses that they had received no training with regard to death, by $50.0 \%$ that they had witnessed the death of someone close to them, by $80 \%$ that if they were at a stage where their own death was close, they would want to know about it, and by $83.3 \%$ that they wished to die at home. A majority of the nurses in our study $(86.2 \%)$ believed terminal stage health care in Turkey to be inadequate; $46.7 \%$ thought that they themselves were partially inadequate with regard to terminal stage patient care, and a majority (76.4\%) wanted to have psychosocial training in final stage patient care (Table 2).

Table 2 General views of nurses to death

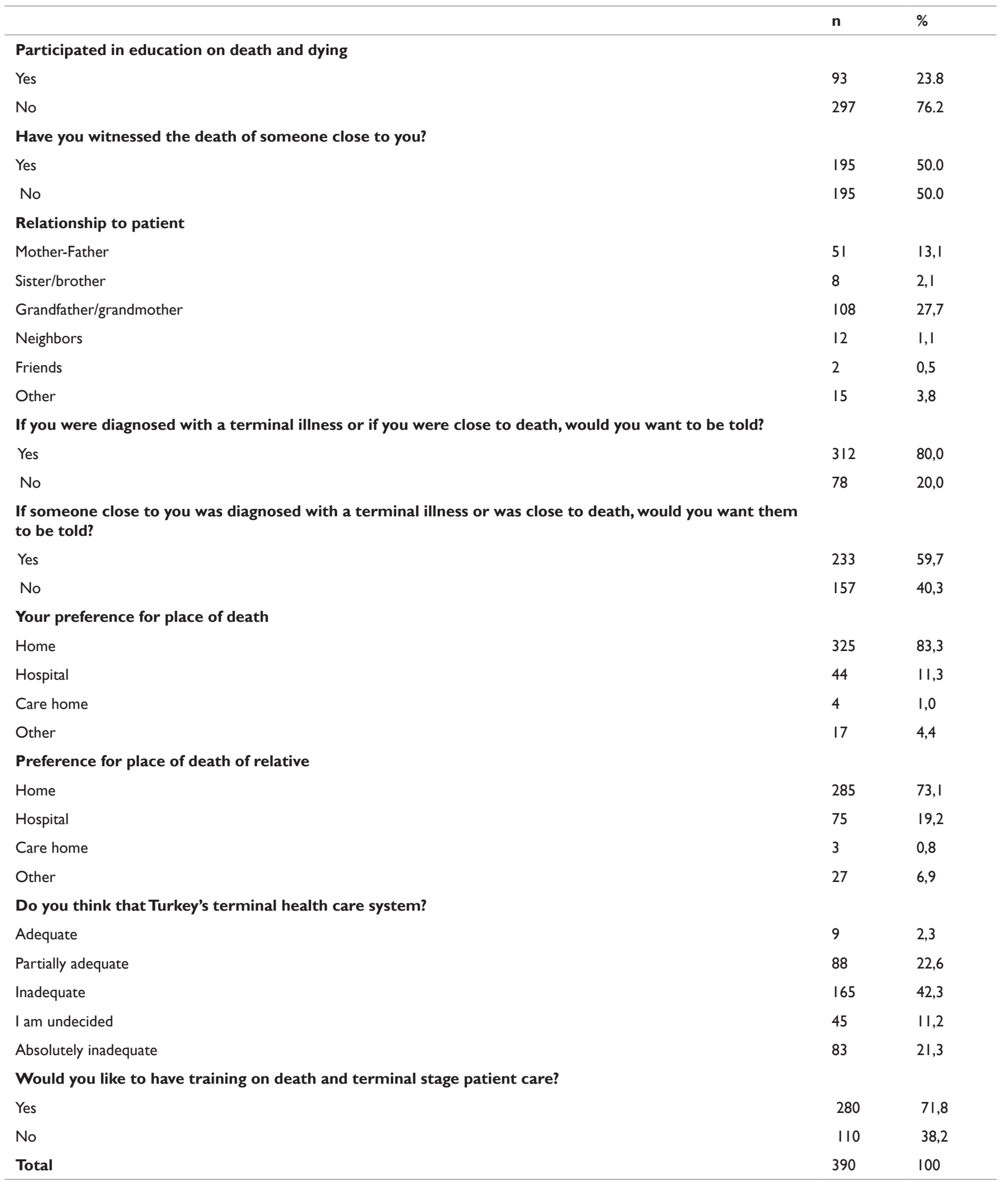


The nurses' mean scores on the DAP-R were as follows: fear of death $4.7 \pm 1.18$, avoidance of death $3.92 \pm 1.28$, neutral acceptance of death 5.22 \pm 0.88 , approach-oriented acceptance of death $4.69 \pm 0.94$, and escape-oriented acceptance of death $3.59 \pm 1.16$ (Table 3). Looking at the nurses' characterizations of a "good" death, it was seen that $28.7 \%$ characterized it as a death free of pain and suffering, $25.9 \%$ said they hadn't thought about it, $19.7 \%$ defined it as a peaceful death with those close to them present, $10.3 \%$ as dying with a clear conscience, $7.9 \%$ as dying knowing that all possible treatments had been administered, and $7.4 \%$ as dying without the need for care (Figure 1).
Table 3 Attitudes towards death and caring for dying patients

\begin{tabular}{lll}
\hline & $\mathbf{X}$ & SD \\
\hline Fear of death & 4,07 & 1,18 \\
Death avoidance & 3,92 & 1,28 \\
Neutral acceptance & 5,22 & 0,88 \\
Appoach acceptance & 4,69 & 0,94 \\
Escape acceptance & 3,59 & 1,16 \\
\hline
\end{tabular}

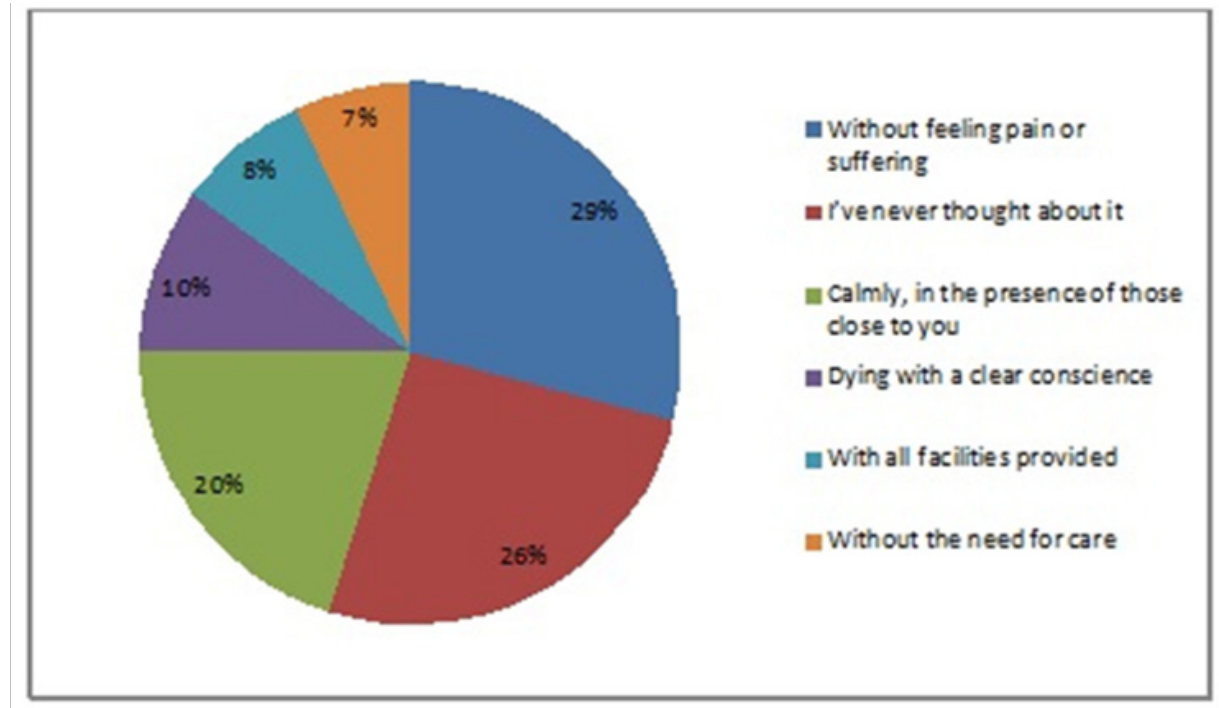

Figure I Nurses interpretation of a dignified death.

Among factors affecting attitudes to death, a positive correlation was found between age and escape-oriented acceptance of death $(\mathrm{p}=0.001, \mathrm{r}: 0.168)$, and a statistically significant relationship was found between marital status and fear of death, between education (professional experience) and escape-oriented acceptance and neutral acceptance of death, and between place of work and neutral and approach-oriented acceptance of death $(\mathrm{p}<0.05)$ (Table 4$)$.

Table 4 Mean scores on DAP and correlation with demographic variables

\begin{tabular}{llllll}
\hline & $\begin{array}{l}\text { Fear of } \\
\text { death }\end{array}$ & $\begin{array}{l}\text { Death } \\
\text { avoidance }\end{array}$ & $\begin{array}{l}\text { Neutral } \\
\text { acceptance }\end{array}$ & $\begin{array}{l}\text { Approach } \\
\text { acceptance }\end{array}$ & $\begin{array}{l}\text { Escape } \\
\text { acceptance }\end{array}$ \\
\hline Marital status & & & & & \\
Married $(n=231)$ & $4.19 \pm 1.07$ & $3.97 \pm 1.21$ & $5.28 \pm 0.82$ & $4.75 \pm 0.91$ & $3.67 \pm 1.13$ \\
Single $(n=146)$ & $3.87 \pm 1.31$ & $3.82 \pm 1.37$ & $5.13 \pm 0.94$ & $4.56 \pm 0.96$ & $3.45 \pm 1.22$ \\
Widowed $(n=13)$ & $4.21 \pm 1.14$ & $4.18 \pm 3.92$ & $4.75 \pm 0.92$ & $5.09 \pm 1.12$ & $3.76 \pm 0.74$ \\
P & $0.019^{*}$ & 0.114 & 0.067 & 0.834 & 0.395 \\
Educational level & & & & & \\
High school $(n=7)$ & $4.26 \pm 1.01$ & $4.08 \pm 1.05$ & $5.02 \pm 0.69$ & $4.38 \pm 0.55$ & $3.82 \pm 1.12$ \\
Associate degree $(n=38)$ & $4.27 \pm 1.17$ & $4.28 \pm 1.24$ & $5.24 \pm 0.82$ & $4.68 \pm 0.81$ & $3.70 \pm 1.21$ \\
Bachelor's degree $(n=3 \mid 7)$ & $4.07 \pm 1.17$ & $3.93 \pm 1.28$ & $5.19 \pm 0.89$ & $4.67 \pm 0.95$ & $3.57 \pm 1.14$ \\
Master's degree $(n=26)$ & $3.76 \pm 1.31$ & $3.32 \pm 1.22$ & $5.65 \pm 0.80$ & $4.90 \pm 1.03$ & $3.61 \pm 1.36$ \\
P & $0,255^{*}$ & $0,021 *$ & $0,044 *$ & 0,354 & 0,886 \\
Having children & & & & & \\
Yes $(n=175)$ & $4.17 \pm 1.13$ & $3.99 \pm 1.25$ & $5.38 \pm 0.80$ & $4.77 \pm 0.97$ & $3.69 \pm 1.13$ \\
No $(n=215)$ & $3.99 \pm 1,22$ & $3.86 \pm 1.30$ & $5.10 \pm 0.92$ & $4.62 \pm 0.91$ & $3.51 \pm 1.17$ \\
\hline
\end{tabular}


Table Continued....

\begin{tabular}{|c|c|c|c|c|c|}
\hline & $\begin{array}{l}\text { Fear of } \\
\text { death }\end{array}$ & $\begin{array}{l}\text { Death } \\
\text { avoidance }\end{array}$ & $\begin{array}{l}\text { Neutral } \\
\text { acceptance }\end{array}$ & $\begin{array}{l}\text { Approach } \\
\text { acceptance }\end{array}$ & $\begin{array}{l}\text { Escape } \\
\text { acceptance }\end{array}$ \\
\hline $\mathbf{P}$ & 0.139 & 0,313 & $0,002 *$ & 0,133 & 0,142 \\
\hline \multicolumn{6}{|l|}{ Workplace } \\
\hline Surgery departments $(n=\mid 48)$ & $4.01 \pm 1,25$ & $3.88 \pm 1.27$ & $5.35 \pm 0.81$ & $4.74 \pm 0.94$ & $3.63 \pm 1.17$ \\
\hline Internal medicine departments $(n=\mid 38)$ & $4.03 \pm 1.19$ & $3.83 \pm 1.40$ & $5.20 \pm 0.90$ & $4.72 \pm 0.98$ & $3.59 \pm 1.12$ \\
\hline Oncology departments $(n=46)$ & $4.36 \pm 1.08$ & $4.14 \pm 1.20$ & $5.23 \pm 0.93$ & $4.5 I \pm 0.85$ & $3.51 \pm 1.39$ \\
\hline Transplantation department $(n=2 I)$ & $4.1 I \pm 0.95$ & $4.01 \pm 1.03$ & $4.65 \pm 0.92$ & $3.48 \pm 0.92$ & $3.69 \pm 1.14$ \\
\hline Anesthesia care unit $(n=37)$ & $4.07 \pm 1.18$ & $3.92 \pm 1.28$ & $5.22 \pm 0.88$ & $3.59 \pm 1.16$ & $3.59 \pm 1.36$ \\
\hline $\mathbf{P}$ & 0.651 & 0,167 & $0,030 *$ & $0,036 *$ & 0.995 \\
\hline
\end{tabular}

$* \mathrm{P} \leq 0.05$.

\section{Discussion}

\section{End of life patient care services and nurses' training needs}

Nurses' attitudes toward death and dying strongly influence the care they deliver to terminally ill patients. Nurses, as part of the healthcare professional team, struggle and find it difficult to deal with death and with dying patients. This struggle is related to a variety of reasons that include nurses' negative personal attitudes concerning death, which, in turn, can make them uncomfortable in providing endof-life care to dying patients.

A study by Frommelt ${ }^{22}$ shown that $76 \%$ of the nurses who participated in the study reported that they were inadequately prepared to deal with dying or terminally ill people. A recent publication by Robinson ${ }^{25}$ reported that in a survey of nurses, $89.5 \%$ reported the importance of end-of-life content for basic nursing education, and yet $62 \%$ indicated that their undergraduate education on end-of-life care was inadequate. ${ }^{25}$ More recently, Beckstrand et al. ${ }^{26}$ commented that health care professionals, mainly nurses, are still inadequately prepared for the care of the dying patients, and suggested that health care professionals should receive education on end-of-life care to overcome this deficiency.

A majority of the nurses in our study $(86.2 \%)$ found terminal stage health care in this Turkey to be inadequate; $46.7 \%$ thought that they themselves were partially inadequate with regard to terminal stage patient care, and a majority $(76.4 \%)$ wanted to have psychosocial training in final stage patient care. The nurses wanted both for themselves and for those close to them to know when they were in the final stage of life, and they wanted to be treated honestly. Healthcare professionals face difficulty in talking to patients and their families about death and the dying period in a phase where curative treatment is not possible. These results in an unsettled attitude to palliative care among health team members and in society at large, and means that death and the dying period are not accepted as an ordinary part of the life cycle. In addition, ethical problems are experienced concerning the participation of dying patients in decision-making related to their treatment. ${ }^{24,27,28}$

Nurses interact with patients very frequently (even more frequently than physicians) during inpatient care, particularly when caring for terminally ill patients. As a result maintaining an open and honest communication with patients can also be a significant challenge for nurses. Research findings on this subject show that Turkish nurses may place significant emphasis on this issue. In a study of 277 Turkish nurses, Ersoy \& Altun ${ }^{29}$ reported that $64 \%$ of the participants shared the opinion that patients should always be told the truth. Similarly, in a study by Ersoy \& $\mathrm{Goz}^{30}$ conducted by presenting hypothetical cases and scenarios to 165 nurses, $76.4 \%$ of the participants were found to favor the disclosure of truthful information to a cancer patient. ${ }^{30}$ However, only $35.4 \%$ of these nurses stated that 'they would give all the information the patient requests', while $30.9 \%$ preferred to 'arrange a talk so that the patient can talk to the doctor' and $11.0 \%$ said they would disclose information 'if the doctor agrees'. These results suggest that physicians' authority can be an important factor that also shapes nurses' approaches to openness in clinical practice. On the other hand, study results obtained from Turkish nursing students and nurses also indicate that patient advocacy is an important concept for nurses. This suggests that a patient-centered approach may be gaining in importance among the members of the Turkish nursing profession. ${ }^{31,32}$

Half of the nurses had witnessed the death of someone they loved, and they stated a preference that they and their loved ones should die at home. For centuries, Turkish people died at home under the care of family and religious rituals were performed at the last moments of life. Urban migration has been one of the forces that have moved nearly $60 \%$ of deaths to hospitals. Another reason for the change in the location of death is the need for female relatives, who used to provide home care to dying persons, to go out to work. Many patients spend their last days traveling to distant hospitals or on long waiting lists for treatment. Dying inpatients are often placed in what healthcare professionals informally call "agonal rooms." These are often in less accessible areas of the hospitals. Patients may receive relatively little attention, and the specific medical needs of persons at the end of life can go unmet. This problem is compounded when such patients are then isolated, which deprives them and their families of important interpersonal communication at the end of life. The dying person is often alone in the institution from which he or she or relatives had sought help..$^{27,33}$

\section{Nurses' attitudes to death}

In their 1987 study, Gesser et al..$^{34}$ developed a Death Attitude Profile (DAP) which identified four independent dimensions of attitude toward death: fear of death/dying, approach-oriented acceptance, escape-oriented acceptance, and neutral acceptance of death. The results of this study suggested that fear of death/dying is negatively related to happiness and positively related to (i.e. increases) hopelessness. Their studies also suggested that escape-oriented acceptance is also positively related to (i.e. increases) hopelessness 
while neutral acceptance is unrelated to hopelessness but positively related to happiness. ${ }^{34}$

Studies have found that people have widely varying attitudes toward death, some positive and some negative, with fear of death being the attitude investigated most frequently. ${ }^{17}$ Nurses' degree of death acceptance, fear of death, and death avoidance might influence their attitudes toward the care of dying patients. ${ }^{16,17,35,36}$ According to Roman et al. ${ }^{20}$ several studies have shown that nurses have negative attitudes toward terminally ill patients in general. ${ }^{20}$ Braun et al. ${ }^{37}$ showed that fear of death was positively correlated with avoidance of death and approach-oriented acceptance, and approach-oriented acceptance was also positively correlated with avoidance of death and escape-oriented acceptance. ${ }^{37}$

Wong et al. ${ }^{23}$ defined each attitude as follows: fear of death is a person's concern or feeling that stems from the failure to find personal meaning for one's life and death; avoidance of death is the attitude that means a person avoids thinking or talking about death; neutral acceptance of death is the attitude that means a person neither welcomes nor denies death; approach-oriented acceptance of death is an attitude that suggests a person believes in a positive afterlife and looks forward to death; escape-oriented acceptance of death is the attitude that leads a person to view death as an alternative to escape from pain and misery in his/her life. ${ }^{4,23}$ In our study, scores for neutral acceptance of death and approach-oriented acceptance were found to be high. According to Wong's definition, it can be thought that the nurses in our study approached death either as something which would not affect them, or as something which everyone would experience and with a belief that after death there is a positive afterlife.

The majority of the Turkish population is Muslim (95\%). Turkish people thus predominantly believe in God and life after death. They believe that suffering during life will be rewarded, even though today many people question these beliefs. According to these religious beliefs, death is the beginning of a new life; death means reaching God, and attaining eternal tranquillity. According to the Muslim holy book, the Koran, "Every soul shall taste death": death is seen as a natural process that everyone will experience. ${ }^{38}$ But many people are unable to meet the death of someone they have been close to in daily life and who they love in the calm and accepting way that this belief and viewpoint requires. The close and deep-rooted relationships which Turkish people establish with those whom they love turn every death into a crisis. What is experienced here in daily life is of course no different from what people in the rest of the world experience when they lose someone they love. However, in Turkish society, mentioning death or dying is still a taboo subject in everyday life. People often do not want to talk about death or anything related to death and dying because it is regarded as an event to be avoided. Death and dying are also considered as something to be feared. All this reveals a negative view of death.

\section{Factors affecting nurses' attitudes to death}

According to Rooda et al. ${ }^{16}$ the factors determining attitudes toward death and caring for dying patients are numerous and complex. These determinants of attitude include cultural, societal, philosophical, and religious belief systems that give meaning to death, as well as the personal and cognitive frameworks within which individuals' attitudes toward death and dying originate and are interpreted. ${ }^{16}$

In our study, the factor of age was shown to have a significant effect on fear of death, neutral acceptance and escape-oriented acceptance. Similarly, in Lange et al..$^{18}$ age was the variable most likely to predict nurses' attitudes toward death and caring for dying patients. When compared with young adults, old adults reported a significantly lower fear of death and a significantly greater neutral acceptance. Old adults reported a significantly greater escape-oriented acceptance than young or middle-aged adults, and a greater approach-oriented acceptance than middle-aged adults. ${ }^{23}$ The results indicated that fear of death/ dying is relatively high among the young, peaks during middle age, and then falls to its lowest level among the elderly. ${ }^{2,23}$ In contrast to this, there are studies in the literature in which the factor of age had no effect on attitudes towards death. Rooda et al. ${ }^{16}$ showed that Death Attitude Profile-Revised score was significantly related to gender, religious affiliation, and current contact with terminally ill patients, but attitudes toward care of the dying were not significantly related to gender, ethnicity, religious affiliation, or level of education, nor to age or nursing experience. ${ }^{16}$

Our study shows that a greater degree of experience of terminal stage patient care and a greater number of years of working increased positive attitudes to death among nurses. Some studies from the literature show that as clinicians gain more experience with terminal and end-of-life care, their attitudes change. ${ }^{9,18,19,22,39,40}$

Bradley et al. ${ }^{19}$ suggested that previous researches of clinicians' attitudes when caring for dying patients created inconsistent results in the literature that made it more complex to achieve a consensus from that literature. ${ }^{19}$ Similarly, in Lange et al. ${ }^{17}$ nursing experience was the variable most likely to predict nurses' attitudes toward death and caring for dying patients. ${ }^{17}$ Dissimilarly, a study Demmer ${ }^{21}$ revealed a significant relationship between personal death-related experience and death anxiety and attitudes toward dying patients. It was found that as years of experience increased, the attitudes of nurses toward dying patients became more negative or were not influenced. ${ }^{21}$

\section{Conclusion}

The nurses in our study thought that terminal stage health care in this Turkey was inadequate, that they themselves were inadequate with regard to terminal stage patient care, and they wanted to have psychosocial training in final stage patient care. It was found that most nurses accepted death neutrally as something which everyone will experience, and those with an approach-oriented acceptance of death met it with the belief in positive afterlife. However, it was concluded that this attitude was not reflected in daily life, that death is often turned into a crisis-situation, and that people in Turkey still treat death as a taboo subject. It was, nevertheless, found that age and professional experience affect attitudes to death.

\section{Acknowledgements}

None.

\section{Funding}

The authors received no financial support for the research, authorship, and/or publication of this article.

\section{Conflict of interest}

The author(s) declared no potential conflicts of interest with respect to the research, authorship, and/or publication of this article.

\section{References}

1. Feifel H. Attitudes toward death: a psychological perspective. J Consult Clin Psychol. 1969;33(3):292-295. 
2. Amy Hui-mei Huang Lin. Factors related to attitudes toward death among Chinese and American older adults. The Degree Doctor of Philosophy in the Graduate School of The Ohio State University, (Doctoral dissertation). Available from ProQuest Dissertations and Theses database; 2000

3. A report from the Economist Intelligence Unit Commissioned by, The quality of death: Ranking end-of-life care across the world. Economist Intelligence Unit; 2010:1-39.

4. Wong FKY, Lee WM, Mok E. Educating nurses to care for the dying in Hong Kong: A problem-based learning approach. Cancer Nurs 2001;24(2):112-121.

5. Babgi AA. Nurses' and Nursing Students' Attitudes toward Death and Dying: A Meta-analysis of the Impact of Educational Interventions. Doctor of Philosophy in Nursing at George Mason University, Fall Semester Fairfax, Virginia (Doctoral dissertation). Available from ProQuest Dissertations and Theses database; 2006.

6. Kubler-Ross E. On death and dying. 2nd ed. New York: MacMillian; 1969:288.

7. Proulx K, Jacelon C. Dying with dignity: The good patient versus the good death. Am J Hosp Palliat Care. 2004;21(2):116-120.

8. Eues KS. End-of-life care improving quality of life at the end of life. Prof Case Manag. 2007;12(6):339-344.

9. Thacker KS. Nurses' advocacy behaviors in end-of-life nursing care Nurs Ethics. 2008;15(2):174-185.

10. Ferrell BR. End of life care: How well do we serve our patients? Nursing 1998;28(9):58-60.

11. Dakin CL. Encouraging student nurses' creative expression about end-of-life experiences. Nurse Educator. 2003;28(4):149-150.

12. Fitch MI. Understanding oncology nurses' experience talking about death and dying. CONJ. 2007;17:132

13. Sasahara T, Miyashita M, Kawa M, et al. Difficulties encountered by nurses in the care of terminally ill cancer patients in general hospitals in Japan. Palliat Med. 2003;17(6):520-526.

14. Miyashita M, Nakai Y, Sasahara T, et al. Nursing autonomy plays an important role in nurses' attitudes toward caring for dying patients. $A m ~ J$ Hosp Palliat Care. 2007;24(3):202-210.

15. Shih FJ, Gau ML, Lin YS, et al. Death and help expected from nurses when dying. Nurse Ethics. 2006;13(4):360-375.

16. Rooda LA, Clement R, Jordan ML. Nurses attitudes toward death and caring for dying patients. Oncol Nurs Forum. 1999;26(10):1683-1687.

17. Neimeyer RA, Wittkowski J, Moser RP. Psychological research on death attitudes: An overview and evaluation. Death Stud. 2004;28(4):309-340.

18. Lange M, Thom B, Kline NE. Assessing nurses' attitudes toward death and caring for dying patients in a comprehensive cancer center. Oncol Nurs Forum. 2008;35(6):955-959.

19. Bradley EH, Cicchetti DV, Fried TR, et al. Attitudes about care at the end-of-life among clinicians:A quick, reliable, and valid assessment instrument. J Palliat Care. 2000;16(1):6-14

20. Roman EM, Sorribes E, Ezquerro O. Nurses' attitudes to terminally ill patients. J Adv Nurs. 2001;34(3):338-345.

21. Demmer C. The relationship between death-related experiences, death anxiety, and patient care attitudes among AIDS nursing staff. $J$ Nurses Staff Dev. 2000;16(3):118-123.
22. Frommelt KH. The effect of death education on nurses' attitudes toward caring for terminally ill persons and their families. Am J Hosp Palliat Care. 1991;8(5):37-43.

23. Wong P, Reker G, Gesser G. Death Attitude Profile-Revised. In: RA Neimeyer RA, editor. Death Anxiety Handbook. Washington, DC: Taylor \& Francis; 1994:120-144.

24. Isık AE, Fadıloglu C, Demir Y. A Study of the Reliability and Validity of the Turkish Version of Death Attitude Profile-Revised (DAP-R) in the Nurse Population. Journal of Research and Development in Nursing. 2009:11(2):28-43

25. Robinson R. End-of-life education in undergraduate nursing curricula Dimens Crit Care Nurs. 2004;23(2):89-92.

26. Beckstrand RL, Callister LC, Kirchhoff KT. Providing a "good death": Critical care nurses' suggestions for improving end-of-life care. Am J Crit Care. 2006;15(1):38-45.

27. Oguz NY, Miles SH, Buken N, et al. End-of-life care in Turkey. Special section: Bioethics Now: International Voices 2003. Cambridge Quarterly of Healthcare Ethics. 2003;12:279-284.

28. Cevik B, Kav S. Attitudes and experiences of nurses toward death and caring for dying patients in Turkey. Cancer Nurs. 2013;36(6):E58-E65.

29. Ersoy N, Altun I. Tendency of nurses to undertake the role of patient advocate. Eubios J Asian Int Bioethics. 1997;7:167-170.

30. Ersoy N, Goz F. The ethical sensitivity of nurses in Turkey. Nurs Ethics. 2001;8(4):299-312.

31. Demirsoy N, Elcioglu O, Yildiz Z. Telling the truth: Turkish patients' and nurses' views. Nurs Sci Q. 2008;21(1):75-79.

32. Guven T. Truth-telling in cancer: Examining the cultural incompatibility argument in Turkey. Nurs Ethics. 2010;17(2):159-166.

33. Aksoy S. End-of-life decision making in Turkey. In: Blank RH, Merrick $\mathrm{JC}$, editors. End-of-life decision making: a cross-national study. Cambridge, Massachusetts: MIT Press; 2005:183-195

34. Gesser G, Wong PTP, Reker GT. Death attitudes across the lifespan: the development and validation of the Death Attitude Profile (DAP). Omega. 1988;18(2):113-125.

35. Dunn KS, Otten C, Stephen E. Nursing experience and the care of dying patients. Oncol Nurs Forum. 2005;32(1):97-104.

36. Rutledge DN, Bookbinder M, Donaldson NE, et al. End-of-life care series. Part 3. Learnings beyond the SUPPORT and HELP studies. The Online Journal of Clinical Innovations. 2001;4(6):1-60.

37. Braun M, Gordon D, Uziely B. Associations between oncology nurses' attitudes toward death and caring for dying patients. Oncology Nursing Forum. 2010;37(1):43-49.

38. Kuran'i Kerim ve Turkce Anlami. (The Koran and Turkish meaning.) Diyanet Isleri Baskanlıg1 Yayını (Publication of the Presidency of Religious Affairs), (in Turkish). 1973

39. Sherman DW, Matzo ML, Pitorak E, et al. Preparation and care at the time of death: content of the ELNEC curriculum and teaching strategies. J Nurses Staff Dev. 2005;21(3):93-100.

40. White KR, Coyne PJ, Patel UB. Are nurses adequately prepared for end-of-life care? J Nurs Scholarsh. 2001;33(2):147-151. 